\title{
Relação de massa e localização do escleródio no solo com germinação carpogênica de Sclerotinia sclerotiorum
}

\author{
Luciano dos Reis Venturoso ${ }^{1}$, Lilian Maria Arruda Bacchi², Walber Luiz Gavassoni ${ }^{2}$, Lenita Aparecida Conus ${ }^{1}$, Bruno \\ Cesar Alvaro Pontim ${ }^{3}$
}

\begin{abstract}
${ }^{1}$ Professores do Instituto Federal de Rondônia, Campus Ariquemes, Rodovia RO, 257, km 13, sentido Machadinho do Oeste, Caixa Postal 130, CEP 76870-970, Ariquemes-RO. ${ }^{2}$ Professores do curso de Agronomia da Universidade Federal da Grande Dourados, Faculdade de Ciências Agrárias, Dourados-MS. ${ }^{3}$ Doutorando em Produção Vegetal da Universidade Federal da Grande Dourados, Dourados-MS.

Autor para correspondência: Luciano dos Reis Venturoso (luciano.venturoso@ifro.edu.br)

Data de chegada: 25/02/2013. Aceito para publicação em: 06/01/2014.
\end{abstract}

1868

\section{RESUMO}

Venturoso, L.R.; Bacchi, L.M.A.; Gavassoni, W.L.; Conus, L.A.; Pontim, B.C.A. Relação de massa e localização do escleródio no solo com germinação carpogênica de Sclerotinia sclerotiorum. Summa Phytopathologica, v.40, n.1, p.29-33, 2014.

Escleródios de Sclerotinia sclerotiorum permitem ao fungo conservar seu poder patogênico por vários anos no solo, todavia, são incipientes os estudos que relacionam a massa e a localização dos escleródios no solo com sua patogenicidade. Desta forma, objetivou-se avaliar se a massa dos escleródios e a sua localização no solo podem interferir na germinação carpogênica de $S$. sclerotiorum. Os escleródios foram pesados e classificados em seis classes, (C1) escleródios com massa inferior a $0,01 \mathrm{~g},(\mathrm{C} 2) 0,01<0,02 \mathrm{~g}$, (C3) 0,02<0,03 g, (C4) 0,03<0,04 g, (C5) 0,04<0,05 g e (C6) 0,05<0,06 g. Depois, foram acondicionados em caixas gerbox contendo solo umedecido até $100 \%$ da saturação, sendo alocados na superfície do solo e enterrados a uma profundidade de $3 \mathrm{~cm}$. Os gerbox foram incubados em câmara BOD, temperatura de $20^{\circ} \mathrm{C}$ e fotoperíodo de $12 \mathrm{~h}$. Notou-se maior percentual de germinação carpogênica nos escleródios colocados na superfície do solo em todas as classes analisadas. Foi observada uma tendência em aumentar a germinação carpogênica com o aumento na massa dos escleródios, constatando-se nos escleródios colocados na superfície, germinação de 37,$5 ; 62,5 ; 75 ; 87,5 ; 100$ e $100 \%$, enquanto que para os escleródios enterrados foi de $0 ; 37,5 ; 37,5 ; 62,5 ; 62,5$ e $62,5 \%$, nas classes C1, C2, C3, C4, C5 e C6, respectivamente. Ao final das avaliações, os escleródios enterrados apresentaram menor número de estipes e apotécios. Os escleródios C4, C5 e C6, quando na superfície do solo originaram mais estipes e apotécios, enquanto que para os enterrados, apenas os escleródios C5 e C6 proporcionaram maior número de estipes e apotécios por escleródio.

Palavras-chave adicionais: massa de escleródio, profundidade de escleródio, fonte de inóculo

\section{ABSTRACT}

Venturoso, L.R.; Bacchi, L.M.A.; Gavassoni, W.L.; Conus, L.A.; Pontim, B.C.A. Relationship of sclerotium mass and location on the soil with carpogenic germination of Sclerotinia sclerotiorum. Summa Phytopathologica, v.40, n.1, p.29-33, 2014.

Sclerotia of Sclerotinia sclerotiorum allow the fungus to conserve its pathogenic power for several years on the soil; however, there are incipient studies that relate the sclerotium mass and location on the soil to its pathogenicity. Thus, the aim of this study was to assess if the sclerotium mass and location on the soil can interfere in the carpogenic germination of S. sclerotiorum. Sclerotia were weighed and classified into six classes, (C1) sclerotia with mass inferior to $0.01 \mathrm{~g}$, (C2) $0.01<0.02 \mathrm{~g}$, (C3) $0.02<0.03 \mathrm{~g}$, (C4) $0.03<0.04$ $\mathrm{g}$, (C5) $0.04<0.05 \mathrm{~g}$, and (C6) $0.05<0.06 \mathrm{~g}$. Then, they were stored in gerbox containing soil moistened up to $100 \%$ saturation and were allocated to the soil surface and buried to a 3 -cm depth. Gerboxes were incubated in a BOD chamber, temperature of $20^{\circ} \mathrm{C}$ and $12 \mathrm{~h}$ photoperiod. The percentage of carpogenic germination was higher for sclerotia that were placed on the soil surface in all analyzed classes. Carpogenic germination tended to increase with the increase in the sclerotium mass; for the sclerotia placed on the soil surface, germination was $37.5,62.5,75,87.5,100$ and $100 \%$, while for buried sclerotia, it was 0 , $37.5,37.5,62.5,62.5$ and $62.5 \%$ in $\mathrm{C} 1, \mathrm{C} 2, \mathrm{C} 3, \mathrm{C} 4, \mathrm{C} 5$ and C6, respectively. At the end of evaluations, buried sclerotia had fewer stipites and apothecia. On the soil surface, C4, C5 and C6 sclerotia originated more stipites and apothecia, while for buried sclerotia only $\mathrm{C} 5$ and $\mathrm{C} 6$ provided larger number of stipites and apothecia per sclerotium.

Additional keywords: sclerotium mass, sclerotium depth, inoculum source

O fungo Sclerotinia sclerotiorum (Lib.) de Bary está entre os patógenos mais importantes do ponto de vista agronômico para diversas culturas. O patógeno faz parte de um grupo de fitopatógenos habitantes do solo, de difícil controle, pois ataca inúmeras culturas e sobrevive por anos no solo conservando seu poder patogênico, por meio de estruturas de resistência denominadas escleródios $(2,15)$.
Os escleródios são estruturas compostas por múltiplas hifas agregadas. Três fases distintas foram reconhecidas durante seu desenvolvimento: a agregação de hifas, o desenvolvimento no tamanho, juntamente com a exsudação de gotículas em sua superfície, e a maturação, envolvendo o delineamento e deposição de melanina, seguido da consolidação interna (14). A deposição de melanina é 
responsável pela redução da permeabilidade e proteção do escleródio contra agentes deletérios (15). De acordo com Liang et al. (8), a indução e o desenvolvimento dos escleródios exigem processos metabólicos e físiológicos específicos, sem os quais, o processo não ocorreria.

Os escleródios são induzidos a germinar, seja de forma miceliogênica, apresentando hifas vegetativas, ou carpogênica, por meio de apotécios capazes de produzir milhões de ascósporos. Ambos podem resultar em infecções nas plantas, todavia, maior potencial epidêmico tem sido verificado pelos ascósporos liberados na germinação carpogênica (1). Vale salientar que a ocorrência da germinação é determinada pela interação de fatores ambientais, os quais incluem temperatura, umidade do solo e a intensidade de luz $(9,16)$. A germinação dos escleródios também pode ser estimulada, por exsudatos radiculares e pelo microclima formado sob o dossel da espécie hospedeira (6).

Quando as condições ambientais não são favoráveis no campo, os escleródios permanecem viáveis até terem acesso ao substrato preferencial (12). Todavia, a viabilidade não deve ser generalizada para diferentes condições edafoclimáticas, pois tem-se verificado divergências no tempo de sobrevivência dos escleródios (15). O sistema de cultivo também apresenta capacidade de afetar a viabilidade das estruturas de resistência, como demonstrado por Reis \& Tomazini (13), que relataram 14 meses em semeadura direta e 36 meses em semeadura convencional.

Outros fatores também agem como condicionantes da germinação carpogênica, como a localização do escleródio no solo (16), o tamanho dos escleródios (9), podendo-se acrescentar a estes a massa dos escleródios. Mueller et al. (10) demonstraram que a aração profunda diminui a infecção causada por S. sclerotiorum, a formação de apotécios e a densidade de escleródio no solo, pois o enterrio destes no perfil do solo possibilita condições inadequadas a germinação.

Liberação de ascósporos e sobrevivência, são, portanto, etapas fundamentais do ciclo de vida de $S$. sclerotiorum. O estudo desses fatores, principalmente aqueles relacionados ao solo, é de grande relevância, visto que aproximadamente $90 \%$ do ciclo de vida do patógeno ocorre no solo e, portanto, informações sobre os fatores que venham a interferir nessas etapas não só aumentam a compreensão sobre o patógeno, mas também contribuem para futuras estratégias de controle da doença (3).

Diante do exposto, objetivou-se avaliar se a massa e a localização dos escleródios no solo interferem na germinação carpogênica de $S$. sclerotiorum.

\section{MATERIAL E MÉTODOS}

Escleródios de $S$. sclerotiorum coletados em plantas de soja de lavouras comerciais foram desinfestados, por um minuto, em álcool $50 \%$ e hipoclorito de sódio a $1 \%$, lavados em água destilada e secos em câmara de fluxo de ar sobre papel filtro. Posteriormente, foram acondicionados em placas de Petri contendo meio de batata-dextroseágar (BDA) e incubados em temperatura de $20^{\circ} \mathrm{C}$ e fotoperíodo de $12 \mathrm{~h}$ por sete dias. Para produção dos escleródios, $100 \mathrm{~g}$ de cenoura cortadas em rodela foram colocadas em erlenmeyers e autoclavadas por 20 min a $120^{\circ} \mathrm{C}$. Após seu resfriamento em câmara asséptica, dez discos de $0,9 \mathrm{~cm}$ de diâmetro colonizados com micélio do patógeno foram depositados sobre o substrato e incubados a $20 \pm 2^{\circ} \mathrm{C}$ sob escuro contínuo por seis semanas para a formação dos escleródios.

Os escleródios produzidos foram transferidos para uma peneira e separados do substrato por meio de lavagem em água corrente e secos à temperatura ambiente. Após a secagem das estruturas, as mesmas foram pesadas em balança de precisão, e classificadas em seis classes, (C1) escleródios com massa inferior a 0,01 g, (C2) 0,01<0,02 g, (C3) $0,02<0,03 \mathrm{~g}$, (C4) $0,03<0,04 \mathrm{~g}$, (C5) $0,04<0,05 \mathrm{~g}$ e (C6) 0,05<0,06 g. Os escleródios foram posicionados na superfície e enterrados a $3 \mathrm{~cm}$. Adotou-se o delineamento experimental inteiramente casualizado, em arranjo fatorial $6 \times 2$, com 6 repetições. Cada gerbox correspondeu a uma unidade experimental.

Quarenta e oito escleródios de cada classe foram alocados em cada profundidade: na superfície do solo, sendo levemente pressionados e enterrados com auxílio de um bastão de vidro a uma profundidade de 3 $\mathrm{cm}$, em caixas gerbox preenchidas com solo do tipo Latossolo Vermelho Distroférrico umedecido até $100 \%$ da saturação. Posteriormente, as caixas gerbox foram colocadas em câmara BOD, a uma temperatura de $20 \pm 2^{\circ} \mathrm{C}$ e fotoperíodo de $12 \mathrm{~h}$.

Observaram-se diariamente as caixas gerbox para constatação da germinação carpogênica. Foram considerados germinados os escleródios com presença de pelo menos um estipe, estrutura inicial no processo de germinação carpogênica, visível sobre o solo a olho nu. As avaliações foram realizadas três dias após a verificação da germinação carpogênica do primeiro escleródio, e a partir de então, em intervalo de sete dias, perfazendo 96 dias de incubação.

A cada avaliação foram mensurados o percentual de germinação carpogênica dos escleródios, computando-se o número de estruturas germinadas em relação ao total de escleródios por caixa gerbox, e o número de estipes e de apotécios por escleródio. As avaliações foram consideradas encerradas após a estabilização na germinação dos escleródios.

Os dados foram transformados em $\sqrt{\mathrm{x}+1}$ e submetidos à análise de variância com auxílio do programa SISVAR, e as médias comparadas pelo teste SNK a 5\% de probabilidade.

\section{RESULTADOS E DISCUSSÃO}

A análise estatística dos dados indicou interação significativa para as avaliações do número de estipes e apotécios por escleródio, porém, para a germinação carpogênica houve apenas efeito simples, tanto da localização como da massa dos escleródios. Notou-se maior percentual de germinação carpogênica nos escleródios localizados na superfície do solo em todas as classes analisadas (Tabela 1), verificando-se que o enterrio dos escleródios representou uma redução média de $43,2 \%$ na germinação carpogênica.

Dentre os fatores que influenciam a germinação, pode-se mencionar a intensidade de luz, umidade e a temperatura do solo $(9,16)$. A disponibilidade hídrica utilizada no trabalho foi favorável à germinação dos escleródios, conforme Napoleão et al. (11), e desta forma, a temperatura e a luminosidade poderiam ser os fatores envolvidos na menor germinação dos escleródios acondicionados a $3 \mathrm{~cm}$. Todavia, Liu \& Paul (9) demonstraram que escleródios em uma profundidade de 5 a $10 \mathrm{~cm}$ do solo podem germinar sem luz e que o fato de se enterrar os escleródios no solo não impede a sua germinação carpogênica, tampouco, a possibilidade de ocorrência da doença pelo patógeno. No entanto, verificou-se no trabalho que o enterrio, mesmo que pouco, proporcionou a menor germinação carpogênica dos escleródios, podendo significar maior redução na fonte de inóculo de S. sclerotiorum.

Foi observada tendência em aumentar a germinação carpogênica com o aumento na massa dos escleródios, constatando-se para os escleródios das classes C5 e C6 germinação média de 81,3\%, enquanto que para os escleródios da classe $\mathrm{C} 1$ a germinação foi de apenas $18,8 \%$, 
Tabela 1. Percentual de germinação carpogênica de escleródios de Scherotinia sclerotiorum de diferentes massas submetidos ao enterrio ou posicionados na superfície do solo.

\begin{tabular}{|c|c|c|c|c|c|c|c|}
\hline \multirow{3}{*}{$\begin{array}{c}\text { Posição } \\
\text { do Escleródio }\end{array}$} & \multicolumn{6}{|c|}{ Classes de Massa de Escleródios (g) } & \multirow[t]{3}{*}{ Média } \\
\hline & $<0,01$ & $0,01<0,02$ & $0,02<0,03$ & $0,03<0,04$ & $0,04<0,05$ & $0,05<0,06$ & \\
\hline & $\mathrm{C} 1$ & $\mathrm{C} 2$ & $\mathrm{C} 3$ & $\mathrm{C} 4$ & $\mathrm{C} 5$ & C6 & \\
\hline Enterrado & 0,0 & 37,5 & 37,5 & 62,5 & 62,5 & 62,5 & $43,8 \mathrm{~b}$ \\
\hline Média & $18,8 \mathrm{c}$ & $50,0 \mathrm{~b}$ & $56,3 \mathrm{~b}$ & $75,0 \mathrm{a}$ & $81,3 \mathrm{a}$ & $81,3 \mathrm{a}$ & \\
\hline
\end{tabular}

Médias seguidas pela mesma letra na linha ou coluna, não diferem entre si pelo teste SNK a 5\% de probabilidade.

o que representa uma redução de $76,9 \%$ em relação às maiores classes. Vale salientar, dentre os valores encontrados, os $100 \%$ de germinação carpogênica alcançado pelas classes C5 e C6 quando os escleródios estavam distribuídos na superfície do solo e a ausência de germinação para àqueles da classe $\mathrm{C} 1$ alocados $\mathrm{a} 3 \mathrm{~cm}$ de profundidade. Hao et al. (7), avaliando a germinação de escleródios de diferentes tamanhos de Sclerotinia minor e S. sclerotiorum, verificaram germinação de $100 \%$ para os maiores escleródios, ao passo que os menores apresentaram apenas 30\% de germinação carpogênica.

Tem sido sugerido que a maior quantidade de reservas dos escleródios estaria relacionada ao seu tamanho. Seria difícil precisar a similaridade da massa dos escleródios com o tamanho dos mesmos, no entanto, se a estrutura de resistência apresenta maior massa, é plausível afirmar que ela também teria maior quantidade de materiais de reserva, e desta forma, maior possibilidade de germinação, visto que, segundo Görgen et al. (6), os materiais de reserva são metabolizados, sintetizados e utilizados na formação de estipes e diferenciação dos apotécios.

Na Tabela 2 são apresentados os dados desdobrados do número de estipes por escleródio. Nota-se maior velocidade de germinação e consequente formação de estipes dos escleródios posicionados na superfície do solo, fato evidenciado pela mensuração de estipes, aos 68 dias após a incubação (DAI), em todas as classes de escleródios. Quando as estruturas de resistência foram enterradas, a massa foi o fator diferencial na velocidade com que os estipes se formaram, constatando a sua germinação aos 68 DAI para as classes C5 e C6, aos 75 DAI para $\mathrm{C} 4$, enquanto que nos escleródios $\mathrm{C} 2$ e $\mathrm{C} 3$ os estipes se tornaram visíveis apenas aos 82 dias após a instalação do ensaio.

Independente da localização, observou-se, de modo geral, incremento no número de estipes com o aumento da massa dos escleródios. Para os escleródios colocados na superfície, logo a partir da primeira avaliação, foi verificado incremento no número de estipes nas classes C4, C5 e C6, as quais não diferiram entre si. Em relação aos

Tabela 2. Número de estipes por escleródios de Scherotinia sclerotiorum de diferentes massas submetidos ao enterrio ou posicionados na superfície do solo.

\begin{tabular}{|c|c|c|c|c|c|c|}
\hline \multirow{3}{*}{$\begin{array}{c}\text { Posição } \\
\text { do Escleródio }\end{array}$} & \multicolumn{6}{|c|}{ Classes de Massa de Escleródios (g) } \\
\hline & $<0,01$ & $0,01<0,02$ & $0,02<0,03$ & $0,03<0,04$ & $0,04<0,05$ & $0,05<0,06$ \\
\hline & $\mathrm{C} 1$ & $\mathrm{C} 2$ & $\mathrm{C} 3$ & $\mathrm{C} 4$ & $\mathrm{C} 5$ & C6 \\
\hline \multicolumn{7}{|c|}{68 dias após a incubação } \\
\hline Superficial & $0,13 \mathrm{Ab}$ & $0,38 \mathrm{Ab}$ & $0,38 \mathrm{Ab}$ & $1,44 \mathrm{Aa}$ & $1,25 \mathrm{Aa}$ & $1,38 \mathrm{Aa}$ \\
\hline Enterrado & $0,0 \mathrm{Aa}$ & $0,0 \mathrm{Ba}$ & $0,0 \mathrm{Ba}$ & $0,0 \mathrm{Ba}$ & $0,50 \mathrm{Ba}$ & $0,50 \mathrm{Ba}$ \\
\hline $\mathrm{CV}$ & \multicolumn{6}{|c|}{$9,72 \%$} \\
\hline \multicolumn{7}{|c|}{75 dias após a incubação } \\
\hline Superficial & $0,19 \mathrm{Ab}$ & $0,75 \mathrm{Ab}$ & $0,50 \mathrm{Ab}$ & $2,06 \mathrm{Aa}$ & $1,94 \mathrm{Aa}$ & $2,00 \mathrm{Aa}$ \\
\hline Enterrado & $0,0 \mathrm{Aa}$ & $0,0 \mathrm{Ba}$ & $0,0 \mathrm{Aa}$ & $0,13 \mathrm{Ba}$ & $0,63 \mathrm{Ba}$ & $0,75 \mathrm{Ba}$ \\
\hline $\mathrm{CV}$ & \multicolumn{6}{|c|}{$13,04 \%$} \\
\hline \multicolumn{7}{|c|}{82 dias após a incubação } \\
\hline Superficial & $0,25 \mathrm{Ac}$ & $1,00 \mathrm{Ab}$ & $0,50 \mathrm{Abc}$ & $2,56 \mathrm{Aa}$ & $2,50 \mathrm{Aa}$ & $2,63 \mathrm{Aa}$ \\
\hline Enterrado & $0,0 \mathrm{Ab}$ & $0,38 \mathrm{Bab}$ & $0,13 \mathrm{Aab}$ & $0,38 \mathrm{Bab}$ & $0,75 \mathrm{Bab}$ & $0,88 \mathrm{Ba}$ \\
\hline $\mathrm{CV}$ & \multicolumn{6}{|c|}{$11,92 \%$} \\
\hline \multicolumn{7}{|c|}{89 dias após a incubação } \\
\hline Superficial & $0,38 \mathrm{Ac}$ & $1,00 \mathrm{Ab}$ & $0,88 \mathrm{Ab}$ & $2,75 \mathrm{Aa}$ & $2,63 \mathrm{Aa}$ & $2,75 \mathrm{Aa}$ \\
\hline Enterrado & $0,0 \mathrm{Ac}$ & $0,38 \mathrm{Bbc}$ & $0,38 \mathrm{Bbc}$ & $0,63 \mathrm{Bb}$ & $1,25 \mathrm{Ba}$ & $1,00 \mathrm{Bab}$ \\
\hline $\mathrm{CV}$ & \multicolumn{6}{|c|}{$9,15 \%$} \\
\hline \multicolumn{7}{|c|}{96 dias após a incubação } \\
\hline Superficial & $0,38 \mathrm{Ac}$ & $1,00 \mathrm{Ab}$ & $1,00 \mathrm{Ab}$ & $2,88 \mathrm{Aa}$ & $2,75 \mathrm{Aa}$ & $2,88 \mathrm{Aa}$ \\
\hline Enterrado & $0,0 \mathrm{Ac}$ & $0,38 \mathrm{Bbc}$ & $0,50 \mathrm{Bbc}$ & $0,63 \mathrm{Bb}$ & $1,38 \mathrm{Ba}$ & $1,25 \mathrm{Ba}$ \\
\hline $\mathrm{CV}$ & \multicolumn{6}{|c|}{$9,08 \%$} \\
\hline
\end{tabular}

Médias seguidas pela mesma letra, minúscula na linha ou maiúscula na coluna, não diferem entre si pelo teste SNK a 5\% de probabilidade. 
escleródios enterrados, apenas as estruturas classificadas como C5 e C6 apresentaram superioridade comparado aos demais. Estes resultados tornam evidente o efeito dos materiais de reserva dos escleródios, onde aqueles com maior massa e consequentemente maior reserva germinaram mais rápido e apresentaram maior quantidade de estipes.

Ao final das avaliações, em todas as classes analisadas, constatouse maior número de estipes por escleródio quando as estruturas de resistência foram colocadas na superfície do solo, sendo verificado um incremento médio de $54,4 \%$ em relação aos enterrados. De acordo com Duncan et al. (5) a viabilidade dos escleródios é reduzida conforme aumenta-se a profundidade de enterrio dos mesmos.

O número de estipes por escleródio verificado na pesquisa foi menor àqueles encontrados por Costa \& Costa (4). Os autores observaram que o solo não cultivado, o mesmo tipo de solo utilizado no trabalho, apresenta características supressivas evidenciadas por retardamento do aparecimento de estipes e formação mais lenta dos apotécios, além de uma redução do número de estipes e apotécios formados, em relação ao solo cultivado.

Os primeiros apotécios foram observados aos 75 DAI, nas classes C4, C5 e C6 na superfície do solo, e apenas na C5 e C6 para os escleródios enterrados (Tabela 3). No final das avaliações constatouse que os escleródios da classe C5 e C6 enterrados a $3 \mathrm{~cm}$ no solo apresentaram maior quantidade de apotécios comparado às demais classes. Quando os escleródios foram posicionados na superfície do solo, o número de apotécios foi significativamente superior nas classes C4, C5 e C6. Hao et al. (7) relataram que o número de estipes e apotécios produzidos por $S$. sclerotiorum e $S$. minor foi altamente correlacionado com o tamanho de escleródios. Os autores sugerem que existe um limite de tamanho abaixo do qual os escleródios não produzam apotécios, fato que explicaria, em parte, a rara produção de apotécios em escleródios de $S$. minor na natureza, uma vez que nestas condições, o patógeno normalmente apresenta escleródios pequenos.

Nota-se que os escleródios de maior massa, dentro de cada localização, apresentaram maior número de apotécios, podendo-se afirmar que o aumento na massa dos escleródios representa maior potencial infectivo às estruturas de resistência de S. sclerotiorum. Para Hao et al. (7) os fragmentos menores de escleródios podem não possuir reservas suficientes para apoiar a produção de apotécios. Enfatiza-se, no entanto, que $100 \%$ dos estipes formados nos escleródios das classes C2 e C1 superficial, se diferenciaram em apotécios, enquanto nas classes de maiores massas, o percentual variou de 72,5 a 90,2\%. Este dado nos permite inferir que os escleródios de menor massa, exceção à classe $\mathrm{C} 1$ enterrada, podem não apresentar a mesma quantidade de inóculo dos escleródios de maiores massas, todavia, são capazes de liberar ascósporos e também causar doença, representando, deste modo, potencial patogênico às culturas.

Em relação à localização das estruturas de resistência, assim como ocorreu para o número de estipes, foi observada maior diferenciação em apotécios dos escleródios acondicionados sobre o solo. Esse comportamento foi similar em todas as classes de massa, constatandose em média $57 \%$ mais apotécios nos escleródios posicionados na superfície. Esse fato pode estar associado a maior sensibilidade de escleródios na superfície do solo às condições de clima, pois, para aqueles enterrados, apesar da pouca profundidade, o solo estaria agindo como uma barreira física, reduzindo a luminosidade e a temperatura próxima aos escleródios e atrasando a sua germinação e consequentemente, a formação de estipes e apotécios.

Ficou evidente que os escleródios localizados na superfície do solo, independente da classe, produziram maior quantidade de propágulos. Esses dados foram verificados em todas as avaliações no decorrer dos períodos de incubação. Considerando-se a maior viabilidade dos escleródios, ao longo do tempo, colocados sobre a superfície do solo (5) e que um único apotécio pode produzir, em um período de até dez dias, 2 a 30 milhões de ascósporos (3), pode-se supor que medidas de manejo que promovam o enterrio dos escleródios resultariam em efetiva redução de propágulos do patógeno.

Tabela 3. Número de apotécios por escleródios de Scherotinia sclerotiorum diferentes massas submetidos ao enterrio ou posicionados na superfície do solo.

\begin{tabular}{|c|c|c|c|c|c|c|}
\hline \multirow{3}{*}{$\begin{array}{c}\text { Posição } \\
\text { do Escleródio }\end{array}$} & \multicolumn{6}{|c|}{ Classes de Massa de Escleródios (g) } \\
\hline & $<0,01$ & $0,01<0,02$ & $0,02<0,03$ & $0,03<0,04$ & $0,04<0,05$ & $0,06<0,05$ \\
\hline & $\mathrm{C} 1$ & $\mathrm{C} 2$ & $\mathrm{C} 3$ & $\mathrm{C} 4$ & $\mathrm{C} 5$ & C6 \\
\hline \multicolumn{7}{|c|}{75 dias após a incubação } \\
\hline Superficial & $0,0 \mathrm{Ab}$ & $0,0 \mathrm{Ab}$ & $0,0 \mathrm{Ab}$ & $0,38 \mathrm{Aa}$ & $0,50 \mathrm{Aa}$ & $0,44 \mathrm{Aa}$ \\
\hline Enterrado & $0,0 \mathrm{Ab}$ & $0,0 \mathrm{Ab}$ & $0,0 \mathrm{Ab}$ & $0,0 \mathrm{Bb}$ & $0,25 \mathrm{Ba}$ & $0,25 \mathrm{Ba}$ \\
\hline $\mathrm{CV}$ & \multicolumn{6}{|c|}{$4,70 \%$} \\
\hline \multicolumn{7}{|c|}{82 dias após a incubação } \\
\hline Superficial & $0,06 \mathrm{Ac}$ & $0,25 \mathrm{Abc}$ & $0,38 \mathrm{Abc}$ & $0,88 \mathrm{Aab}$ & $1,25 \mathrm{Aa}$ & $1,19 \mathrm{Aa}$ \\
\hline Enterrado & $0,0 \mathrm{Aa}$ & $0,0 \mathrm{Aa}$ & $0,0 \mathrm{Aa}$ & $0,06 \mathrm{Ba}$ & $0,63 \mathrm{Ba}$ & $0,63 \mathrm{Aa}$ \\
\hline $\mathrm{CV}$ & \multicolumn{6}{|c|}{$12,06 \%$} \\
\hline \multicolumn{7}{|c|}{89 dias após a incubação } \\
\hline Superficial & $0,25 \mathrm{Ac}$ & $0,50 \mathrm{Abc}$ & $0,88 \mathrm{Ab}$ & $1,88 \mathrm{Aa}$ & $1,94 \mathrm{Aa}$ & $2,00 \mathrm{Aa}$ \\
\hline Enterrado & $0,0 \mathrm{Ab}$ & $0,13 \mathrm{Bb}$ & $0,0 \mathrm{Bb}$ & $0,25 \mathrm{Bb}$ & $0,75 \mathrm{Ba}$ & $0,75 \mathrm{Ba}$ \\
\hline $\mathrm{CV}$ & \multicolumn{6}{|c|}{$8,76 \%$} \\
\hline \multicolumn{7}{|c|}{96 dias após a incubação } \\
\hline Superficial & $0,38 \mathrm{Ac}$ & $1,00 \mathrm{Ab}$ & $0,88 \mathrm{Ab}$ & $2,38 \mathrm{Aa}$ & $2,31 \mathrm{Aa}$ & $2,50 \mathrm{Aa}$ \\
\hline Enterrado & $0,0 \mathrm{Bc}$ & $0,38 \mathrm{Bbc}$ & $0,38 \mathrm{Bbc}$ & $0,50 \mathrm{Bb}$ & $1,00 \mathrm{Ba}$ & $1,13 \mathrm{Ba}$ \\
\hline $\mathrm{CV}$ & \multicolumn{6}{|c|}{$7,07 \%$} \\
\hline
\end{tabular}

Médias seguidas pela mesma letra, minúscula na linha ou maiúscula na coluna, não diferem entre si pelo teste SNK a 5\% de probabilidade. 
Segundo Görgen et al. (6), a severidade do mofo branco em diferentes hospedeiros de $S$. sclerotiorum é, em geral, proporcional à densidade de inóculo do patógeno no solo. Todavia, pelos resultados observados no trabalho, torna-se relevante o conhecimento da localização e massa dos escleródios para se fazer tal inferência. $\mathrm{O}$ que se pode afirmar é que a redução da população de escleródios e da formação de apotécios é imprescindível, dentre as estratégias de manejo da doença.

Pode-se concluir que o enterrio dos escleródios reduz o potencial patogênico de $S$. sclerotiorum e que os escleródios com maior massa e localizados na superfície do solo apresentam maior potencial patogênico, evidenciado pelo maior percentual de germinação carpogênica, número de estipes e apotécios por escleródio.

\section{AGRADECIMENTOS}

A CAPES pela concessão da bolsa. Ao programa de Pós-graduação em Agronomia da Universidade Federal da Grande Dourados.

\section{REFERÊNCIAS BIBLIOGRÁFICAS}

1. Bolton, M. D.; Thomma, B. P. H. J.; Nelson, B. D. Sclerotinia sclerotiorum (Lib.) de Bary: biology and molecular traits of a cosmopolitan pathogen. Molecular Plant Pathology, Oxford, v. 7, n. 1, p. 1-16, 2006.

2. Bueno, C. J.; Ambrósio, M. M. Q.; Souza, N. L. Preservação de fungos fitopatogênicos habitantes do solo. Summa Phytopathologica, Botucatu, v. 32, n. 1, p. 42-50, 2006.

3. Clarkson, J. P.; Staveley, J.; Phelps, K.; Young, C. S.; Whipps, J. M. Ascospore release and survival in Sclerotinia sclerotiorum. Mycological Research, Cambridge, v. 107, n. 2, p. 213-222, 2003.

4. Costa, G. R.; Costa, J. L. S. Influência do solo e de substratos para produção de escleródios na germinação carpogênica de Sclerotinia sclerotiorum. Pesquisa Agropecuária Tropical, Goiânia, v. 36, n. 2, p. 83-87, 2006.

5. Duncan, R. W.; Fernando, W. G. D.; Rashid, K. Y. Time and burial depth influencing the viability and bacterial colonization of sclerotia of Sclerotinia sclerotiorum. Soil Biology \& Biochemistry, Cambridge, v. 38, n. 2, p. 275-284, 2006.

6. Görgen, C. A.; Civardi, E. A.; Ragagnin, V. A.; Silveira Neto, A. N.; Carneiro, L. C.; Lobo Junior, M. Redução do inóculo inicial de Sclerotinia sclerotiorum em soja cultivada após uso do sistema Santa Fé. Pesquisa Agropecuária Brasileira, Brasília, v. 45, n. 10, p. 1102-1108, 2010.

7. Hao, J. J.; Subbarao, K. V.; Duniway, J. M. Germination of Sclerotinia minor and $S$. sclerotiorum sclerotia under various soil moisture and temperature combinations. Phytopathology, Saint Paul, v. 93, n. 4, p. 443-450, 2003.

8. Liang, Y.; Rahman, M. H.; Strelkov, S. E.; Kav, N. N. V. Developmentally induced changes in the sclerotial proteome of Sclerotinia sclerotiorum. Fungal Biology, Cambridge, v. 114, n. 8, p. 619-627, 2010.

9. Liu, Y; Paul, V. H. Studies on the germination of sclerotia of Sclerotinia sclerotiorum. Journal of Plant Diseases and Protection, Stuttgart, v. 114, n. 1, p. 14-19, 2007.

10. Mueller, D. S.; Hartman, G. L.; Pedersen, W. L. Effect of crop rotation and tillage system on sclerotinia stem rot on soybean. Canadian Journal of Plant Pathology, Burnaby, v. 24, n. 4, p. 450-456, 2002.

11. Napoleão, R.; Café-Filho, A. C.; Lopes, C. A.; Nasser, L. C. B.; Marouelli, W. A. Efeito da frequência de rega e da umidade do solo sobre a germinação carpogênica de Sclerotinia sclerotiorum. Summa Phytopathologica, Botucatu, v. 33, n. 1, p. 80-82, 2007.

12. Reis, E. M.; Casa, R. T.; Gava, F.; Moreira, É. N.; Sachs, C. Indução da germinação carpogênica de escleródios de Sclerotinia sclerotiorum sob diferentes substratos. Revista de Ciências Agroveterinárias, Lages, v. 10, n. 2, p. 145-150, 2011.

13. Reis, E. M.; Tomazini, S. L. Viabilidade de esclerócios de Sclerotinia sclerotiorum em duas profundidades no solo. Summa Phytopathologica, Botucatu, v. 31, n. 1, p. 97-99, 2005.

14. Townsend, B. B.; Willetts, H. J. The development of sclerotia in certain fungi. Transactions of the British Mycological Society, Londres, v. 37, n. 3, p. 213-221, 1954.

15. Willetts, H. J.; Bullock, S. Developmental biology of sclerotia. Mycological Research, Cambridge, v. 96, n. 10, p. 801-816, 1992.

16. Wu, B. M.; Subbarao, K. V. Effects of soil temperature, moisture, and burial depths on carpogenic germination of Sclerotinia sclerotiorum and S. minor. Phytopathology, Saint Paul, v. 98, n. 10, p. 1144-1152, 2008. 